\title{
Seismic Microzonation in a Small Municipality: The Canazei Case Study (Trentino, N Italy)
}

\author{
Floriana Pergalani, Massimo Compagnoni, Giuseppe Di Capua, \\ Daniela Famiani, Andrea Franceschini, and Alfio Viganò
}

\begin{abstract}
The results of a detailed seismic microzonation study performed at Canazei (TrentinoNorthern Italy) are here presented. We investigated the local seismic response of this small village using a Level 3 seismic microzonation, the most accurate according to the Italian Code of Seismic Microzonation. This method consists of gradual steps of knowledge to consider different aspects of the amplification phenomena. A multidisciplinary approach has been performed, including a local geological study, geophysical investigations, geotechnical characterization of lithologies and numerical analyses. The obtained elastic response spectra were compared to the spectra prescribed by the Italian Building Code. Our results show the geologic and geophysical subsoil heterogeneities, responsible for different local seismic responses in terms of acceleration spectra and amplification factors.
\end{abstract}

\section{Keywords}

Seismic microzonation - Response spectra - Amplification factor

\section{$206.1 \quad$ Introduction}

In the activities finalized to the knowledge of the local seismic hazard and the seismic risk, geological and geophysical studies are essential to perform prevention and reconstruction activities, especially where seismic hazard is related to high building vulnerability and the artistic and historic importance of urban centers.

F. Pergalani $(\bowtie) \cdot$ M. Compagnoni

DICA, Politecnico di Milano, Piazzale Leonardo da Vinci, 20133, Milan, Italy

e-mail: floriana.pergalani@polimi.it

G. Di Capua · D. Famiani

Istituto Nazionale di Geofisica e Vulcanologia, Via Vigna Murata, Rome, Italy

A. Franceschini

Provincia Autonoma di Trento, Trento, Italy

A. Viganò

INOGS, CRS, Via Treviso 55, Udine, Italy
Seismic microzonation evaluates the expected local seismic hazard that originates from the peculiar geological and geomorphological characters of the site, by a multidisciplinary approach and specific levels of in-depth analyses. The Italian Guidelines for the Seismic Microzonation (ICMS) (GdL MS 2008) prescribe 3 levels of knowledge: the Level 1 (qualitative approach) is dedicated to the individuation of the areas where amplification and/or instability phenomena can occur. The Level 2 (semi-quantitative approach) defines the expected amplification factors using abacuses, starting from deposit thicknesses (z) and the equivalent average shear-wave velocity within the $\mathrm{H}$ depth interval $\left(\mathrm{Vs}_{\mathrm{H}}\right)$. The Level 3 (quantitative approach) quantitatively evaluates amplification and instability by applying experimental and numerical analyses.

The Provincia Autonoma di Trento promoted a multidisciplinary study in the small municipality of Canazei with the aim of seismic risk reduction, applying a Level 3 ICMS approach. Principal phases performed by the multidisciplinary working group were: 
- geological and geomorphological survey (scale 1:5,000);

- geophysical characterization of lithologic units and construction of the subsoil physical model, by using Horizontal-to-Vertical Spectral Ratio (HVSR) and other geophysical techniques (MASW, Multi-Channel Analysis of Surface Waves; ERT, Electrical Resistivity Tomography);

- determination of the site-specific seismic motion (i.e., input accelerograms);

- numerical analysis (two-dimensional models) to calculate expected amplification in terms of elastic acceleration response spectra and amplification factors.

\subsection{Deep Structure and Material Properties}

Canazei is located in a typical alpine valley (NE Alps) at about $1,500 \mathrm{~m}$ asl. On the basis of the available geological and Level 1 seismic microzonation maps, local deposits alluvial, landslide debris and colluvial deposits forming alluvial and debris fans. Igneous and sedimentary (mainly carbonate) rocks constitute the local geological bedrock. The geophysical model has been obtained by geophysical site characterization (MASW, HVSR and ERT analyses; Fig. 206.1) along six cross-sections across the valley (Fig. 206.2). Geotechnical and geophysical parameters for each geophysical unit are listed in Table 206.1.

\subsection{Reference Seismic Motion}

The numerical analyses of Level 3 (ICMS) requires realistic accelerograms and acceleration response spectra as seismic input. The maximum acceleration $\left(\mathrm{a}_{\max }\right)$ and the spectral ordinates of the acceleration response spectra (for conventional return periods of 475 years) were calculated according to the Italian seismic hazard map (GdL MPS 2004). The reference $\mathrm{a}_{\max }$ value, obtained by inverse-distance interpolation on four grid points of the study area (cf. GdL MPS 2004), is $0.066 \mathrm{~g}$.

Instrumentally-recorded accelerograms were extracted from the ITACA Database (Working Group ITACA 2010), according to rules prescribed by the National Code (IBC 2008). The five selected accelerograms were scaled in order to have the acceleration peaks close to the reference $a_{\max }$ value (Fig. 206.3).

\subsection{Numerical Modeling and Results}

Due to the observed geological and geophysical complexity, analyses were carried out applying two-dimensional numerical models. The applied numerical code derives from the finite-element Quad4 m code (Hudson et al. 1993) and permits both to model any section characterized by specific materials and to analyze the non-linear soil response by equivalent-linear analyses.

The results are reported as average of the five outputs at specific points of the studied cross-sections, in terms of elastic acceleration response spectra (5\% critical damping, Fig. 206.4) and amplification factors (Fa, Fig. 206.5). Fa is calculated as the ratio between the output and input integrals on the elastic velocity response spectra in the period ranges $0.1-0.5 \mathrm{~s}\left(\mathrm{Fa}_{0.1}-0.5\right)$ and $0.5-1.5 \mathrm{~s}\left(\mathrm{Fa}_{0.5}-1.5\right)$ (Pergalani et al. 1999).

The obtained average acceleration response spectra are compared with the response spectra prescribed by the Italian Building Code (IBC 2008) assuming the correspondent subsoil category for each point (using the $\mathrm{Vs}_{30}$ value) (Fig. 206.4).

To perform this comparison, the calculated spectra were modified using the procedure by GdL MS (2008), producing spectra characterized by three segments with constant

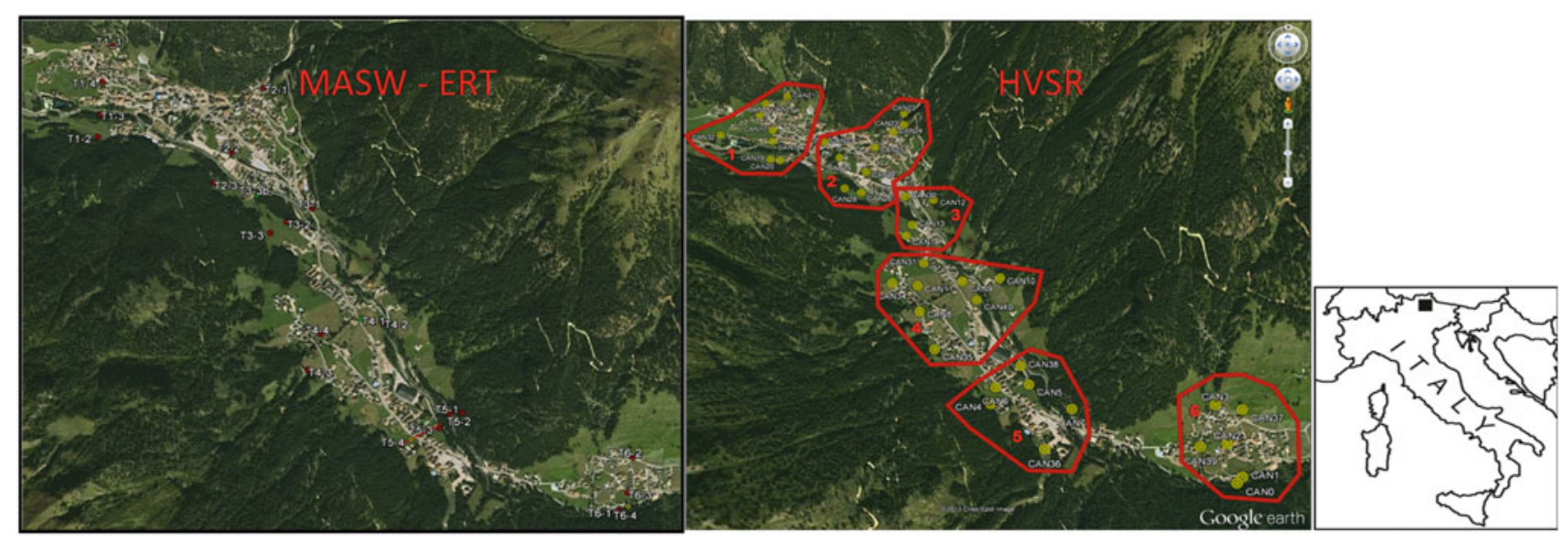

Fig. 206.1 Location of the HVSR, MASW and ERT investigation in the Canazei study area and related key map 

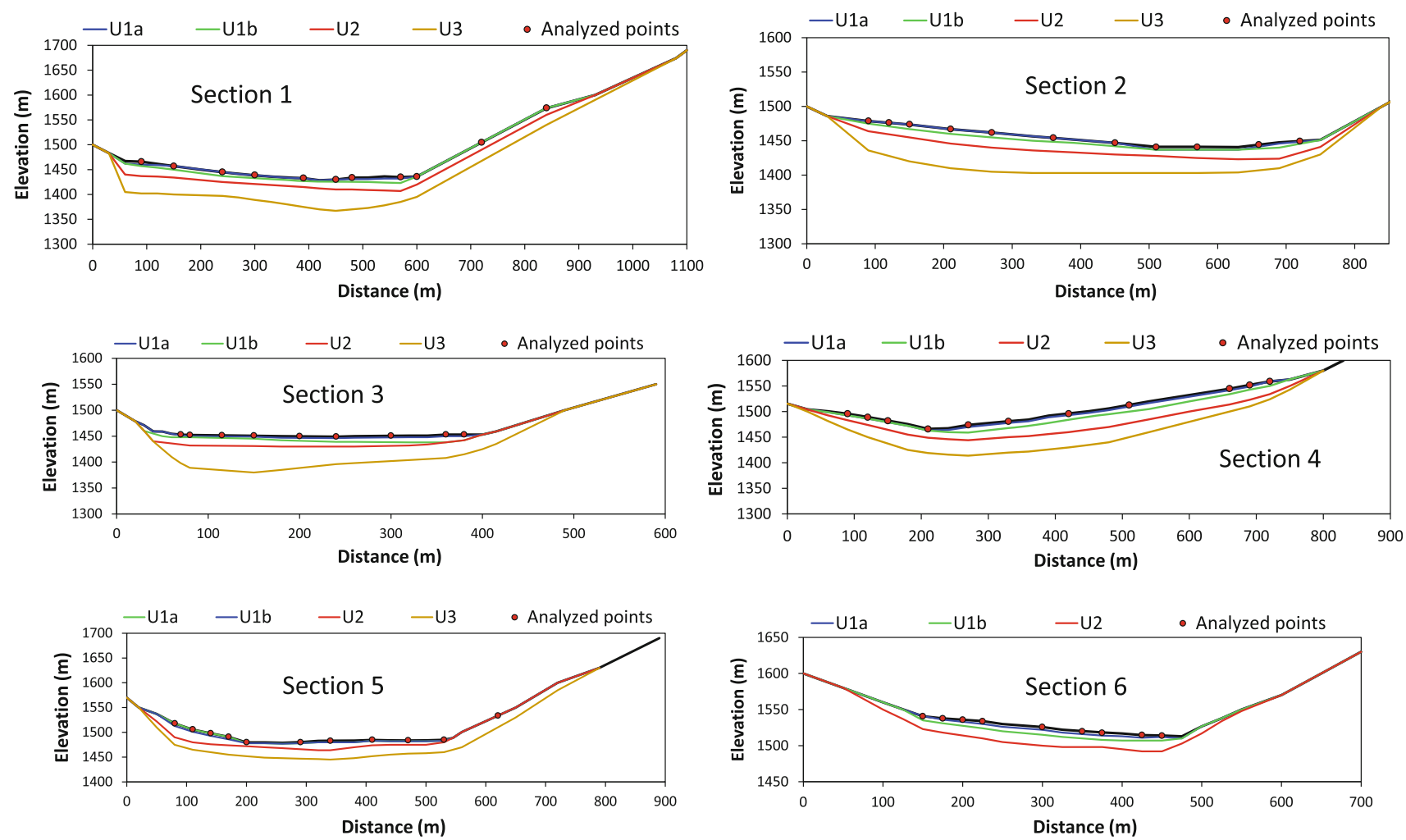

Fig. 2 Geophysical sections referred to the six areas highlighted in Fig. 206.1

Table 206.1 Geotechnical and geophysical parameters used for the numerical analyses

\begin{tabular}{|c|c|c|c|c|c|c|c|c|c|}
\hline \multirow[t]{2}{*}{ Geophysical unit } & \multirow[t]{2}{*}{$\gamma\left(\mathrm{kN} / \mathrm{m}^{3}\right)$} & \multirow[t]{2}{*}{$v(-)$} & \multirow[t]{2}{*}{$\mathrm{D}_{0}(\%)$} & \multicolumn{6}{|l|}{ Vs $(\mathrm{m} / \mathrm{s})$} \\
\hline & & & & Section 1 & Section 2 & Section 3 & Section 4 & Section 5 & Section 6 \\
\hline U1a & 18.5 & 0.40 & 0.010 & \multicolumn{6}{|c|}{200} \\
\hline $\mathrm{U} 1 \mathrm{~b}$ & 19.0 & 0.40 & 0.010 & 270 & 260 & 290 & 310 & 250 & 300 \\
\hline $\mathrm{U} 2$ & 20.0 & 0.45 & 0.010 & 470 & 410 & 490 & 510 & 440 & 520 \\
\hline $\mathrm{U} 3$ & 22.0 & 0.40 & 0.007 & 780 & 670 & 720 & 740 & 680 & - \\
\hline Bedrock & 24.0 & 0.37 & 0.005 & 1,000 & 930 & 1,200 & 1,000 & 940 & 800 \\
\hline
\end{tabular}

$\gamma$ unit weight, $v$ Poisson coefficient, $D_{0}$ initial damping ratio, $V s$ shear-wave velocity

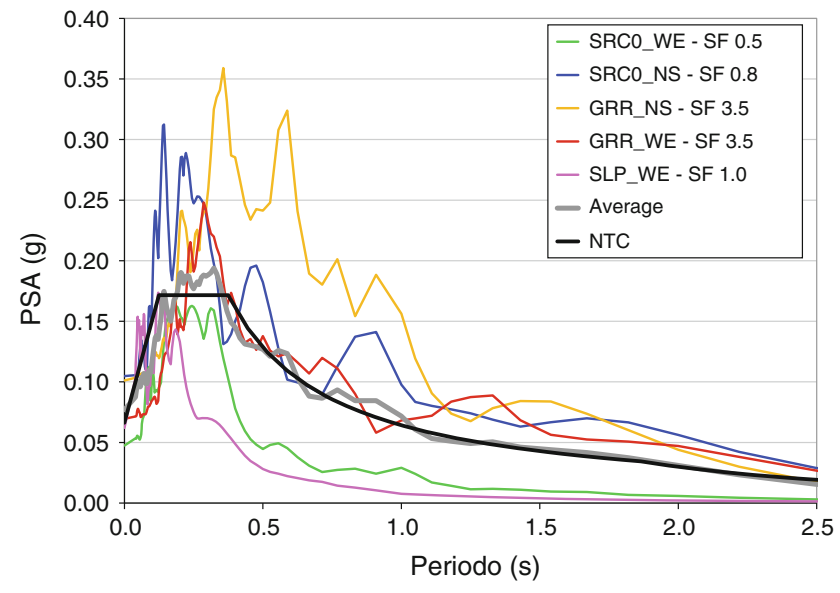

Fig. 206.3 Elastic acceleration response spectra, with average, of the selected input motions (SF, scaling factor),with response spectrum according to IBC (2008) spectral acceleration, spectral velocity and spectral displacement, respectively.

In general, the IBC (2008) spectra are lower than the calculated spectra, particularly for low periods and for B category subsoils (Fig. 206.4).

Figure 206.5 maps the result in terms of average amplification factors, where each singular value at a specific point has been laterally extrapolated considering geologic homogeneity.

$\mathrm{Fa}_{0.1}-0.5$ values locally reach values higher than 2.8 , showing significant amplification. $\mathrm{Fa}_{0.5}-1.5$ values range between 1.0 and 1.8, corresponding to a medium-high amplification. 

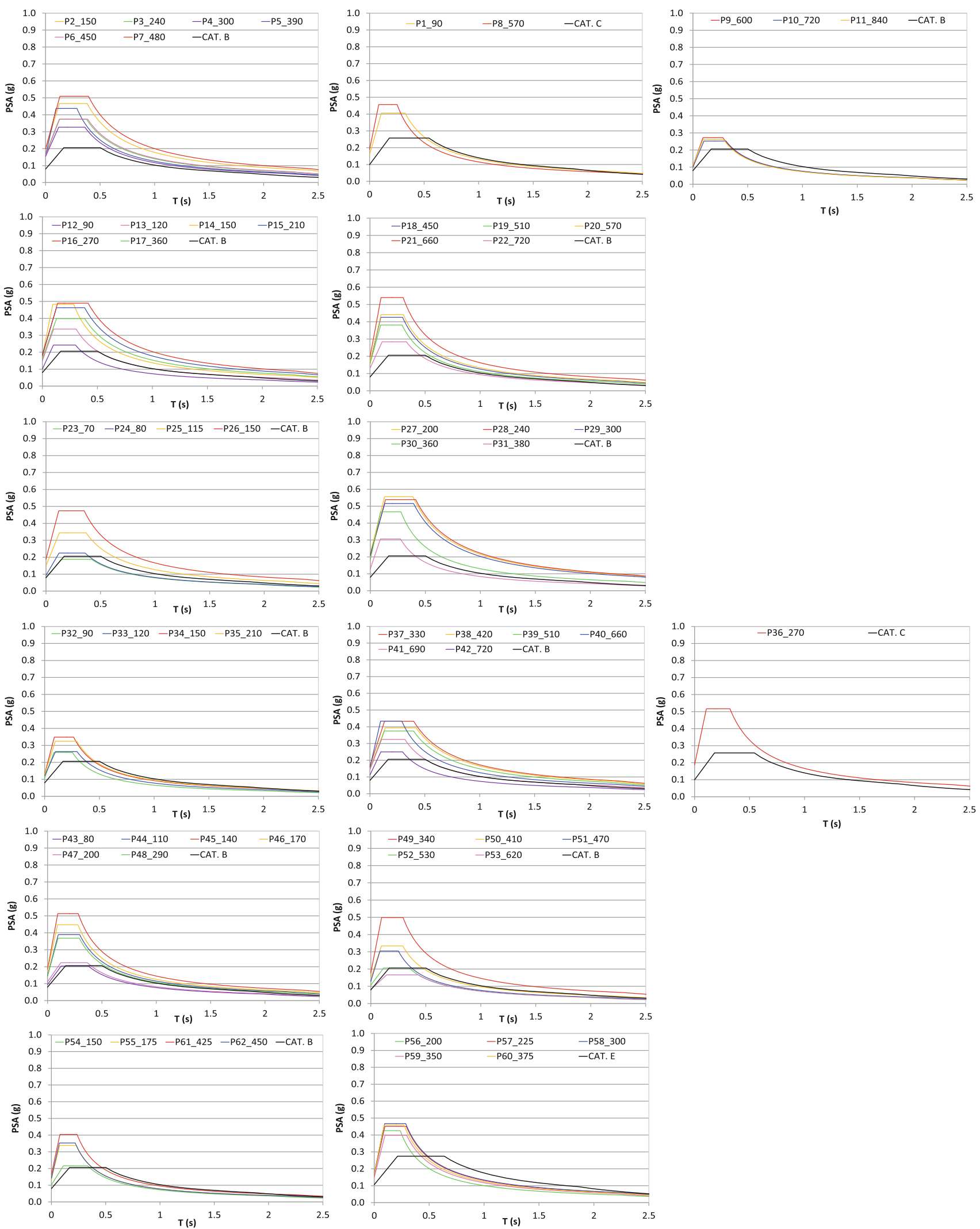

Fig. 206.4 Elastic acceleration response spectra of selected points along each section (cf. Fig. 206.2) from 1 (first row) to 6 (last row), with reference response spectra according to IBC (2008) 
Fig. 206.5 Amplification factor (Fa) maps for periods $0.1-0.5$ and $0.5-1.5 \mathrm{~s}$
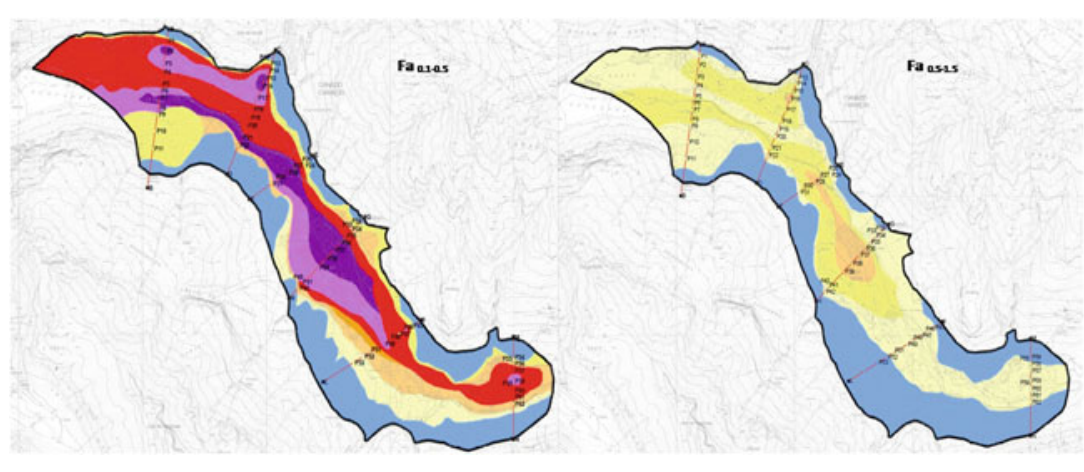

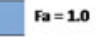

$\mathrm{Fa}=1.1-1.2$ $\mathrm{Fa}=1.3-1.4$ $\mathrm{Fa}=1.5-1.6$ $\mathrm{Fa}=1.7-1.8$ $\mathrm{Fa}=1.9-2.2$ $\mathrm{Fa}=2.3-2.8$ Fa $>2.8$

\subsection{Conclusions}

The Canazei study permitted to highlight geologic and geophysical local heterogeneities of the subsoil, able to produce different local seismic responses. The Level 3 seismic microzonation carefully defines the effective seismic hazard at this site, necessary to evaluate risk for seismic and civil protection.

The results, expressed in terms of elastic acceleration response spectra and amplification factors for specific period intervals, show significant differences with respect to the response spectra of the Italian Building Code (IBC 2008). The use of these new calculated spectra is proposed for building design projects.

We confirm that, in urban contexts, seismic microzonation analyses offer a necessary and valid method to improve knowledge and quantitatively evaluate seismic response useful for risk reduction and building safety improvements.

\section{References}

GdL MPS (2004) Redazione della mappa di pericolosità sismica prevista dall'Ordinanza PCM 3274 del 20 marzo 2003. Rapp. conclusivo per il DPC, INGV, Milano-Roma, pp $65+5$ appendici

GdL MS (2008) Indirizzi e criteri per la microzonazione sismica. Conferenza delle Regioni e delle Province autonome-Dipartimento della Protezione Civile, Roma, Italy, vol 3 Dvd

Hudson MB, Idriss IM, Beikae M (1993) QUAD4 M, A computer program for evaluating the seismic response of soil structure by variable damping finite element procedures. Report of Department of Civil and Environment. Engineering University of California, Davis

IBC (2008) Norme Tecniche per le Costruzioni, DM 14 gennaio 2008, Gazzetta Ufficiale n. 29 del 4 febbraio 2008, Supplemento Ordinario n. 30. Istituto Poligrafico e Zecca dello Stato, Roma (www.cslp.it)

Pergalani F, Romeo R, Luzi L, Petrini V, Pugliese A, Sanò T (1999) Seismic microzoning of the area struck by Umbria-Marche (central Italy) Ms 5.9 earthquake of the 26 September 1997, Soil Dyn. Earthq Eng vol 18, 4, pp 279-296

Working Group ITACA (2010) Data base of the italian strong motion records. http://itaca.mi.ingv.it 